\title{
Influence of diltiazem on bronchoconstriction induced by cold air breathing during exercise
}

\author{
HELGO MAGNUSSEN, VICTOR HARTMANN, GABRIELE REUSS
}

From the Medizinische Universitäts-Poliklinik, Bonn, West Germany

ABSTRACT Since the calcium antagonists nifedipine and verapamil have been shown to diminish exercise induced asthma, the effect of oral diltiazem, a calcium channel blocker not previously investigated in this context, was studied. Ten patients with bronchial asthma were given $60 \mathrm{mg}$ diltiazem or placebo four hours before the challenge in a double blind, randomised, crossover fashion. Exercise was performed on a cycle ergometer while the subjects were breathing cold air, resulting in a respiratory heat exchange which was similar at the two study sessions. $\mathrm{FEV}_{1}$ and specific conductance (sGaw) were recorded before and three, 10, 15, and 30 minutes after the challenge. No significant differences were found between placebo and diltiazem days in the fall of $\mathrm{FEV}_{1}$ or sGaw after exercise. Thus unlike other calcium antagonists diltiazem, in a dose of $60 \mathrm{mg}$ given orally four hours before exercise, failed to protect against exercise induced asthma.

Exercise induced asthma can be completely or partially inhibited by oral nifedipine ${ }^{1-3}$ or by inhaled verapamil. ${ }^{4}$ We have investigated another calcium channel blocker, diltiazem, as no study on its ability to influence exercise induced asthma has previously been reported. As respiratory heat exchange is considered to be an initiating stimulus for exercise induced asthma, ${ }^{5}$ the effects of diltiazem and placebo were compared under carefully controlled experimental conditions designed to standardise the inhalation thermal challenge during exercise.

\section{Methods}

Patients We investigated 10 patients with bronchial asthma (five men and five women with a mean age of 27.9 years, range 19-41). Nine patients were judged atopic on the basis of positive skin test reactions to common allergens. All patients gave a history suggesting exercise induced asthma. All were non-smokers and did not require regular medication. Sympathomimetic agents, which were taken occasionally, were withheld for 12 hours before the study sessions. The patients were instructed about the aim of the study and gave their consent.

Address for reprint requests: Privatdozent Dr Helgo Magnussen, Pneumologische Funktionseinheit, Medizinische UniversitätsPoliklinik, Wilhelmstrasse 35-37, 5300 Bonn, Federal Republic of Germany.

Accepted 14 February 1984
Cold air breathing during exercise Cold air was produced by passing dried room air through a heat exchanger. Inspiratory and expiratory temperatures were measured by two thermocouples situated within the respective ports of a two way HansRudolf valve (W Collins, United States of America). The water content of both inspired and expired air was calculated from standard saturationtemperature relationships ${ }^{6}$ on the assumption of $100 \%$ humidity. Expired air was conducted through a heated pneumotachograph (Fleisch No 4) and airflow was integrated electronically to give tidal volume. Respiratory heat exchange was calculated according to the equation given by Deal et al. ${ }^{5}$

Exercise was performed on a cycle ergometer. Following the method of Deal et al,$^{5}$ the patients breathed cold air for four minutes before exercise, while sitting quietly on a cycle ergometer. The duration of exercise was four minutes and this was followed by a further four minutes during which the subjects continued to breathe cold air through the same mouthpiece. For each patient the work load was adjusted to give a minute ventilation of about $501 \mathrm{~min}^{-1}$, yielding respiratory heat exchange of about $1 \mathrm{kcal}(4 \cdot 184 \mathrm{~kJ}) / \mathrm{min}$.

Lung function measurements Thoracic gas volume at functional residual capacity and specific airways conductance during quiet breathing (sGaw) were measured with a constant volume body plethysmograph $^{7}$ (Bodytest, E Jaeger, West Germany). Inspired vital capacity and $\mathrm{FEV}_{1}$ were measured 
after the plethysmographic manoeuvre. At each time interval three plethysmographic and spirometric measurements were made.

Experimental protocol Four hours before the challenge each patient received either placebo or diltiazem, $60 \mathrm{mg}$, in a double blind, randomised, crossover fashion. Lung function was assessed before (baseline values) and three, 10, 15, and 30 minutes after the challenges, which were performed on different days at the same time of the day. The work load of the ergometer was constant on both occasions.

Evaluation of data The airway response to exercise during the breathing of cold air was assessed by expressing the lowest values of sGaw or FEV observed after the challenge as percentages of the respective baseline values. The effect of diltiazem in comparison with placebo was quantified in terms of a protection index, given by

$\%$ fall in sGaw $\left(\mathrm{FEV}_{1}\right)$ after placebo - \% fall in sGaw $\left(\mathrm{FEV}_{1}\right)$ after diltiazem

$\%$ fall in sGaw $\left(\mathrm{FEV}_{1}\right)$ after placebo

The results were analysed statistically with Friedmann's test of homogeneity and by the multiple, two tailed comparison of Wilcoxon and Wilcox. ${ }^{8}$

\section{Results}

The pre-exercise values of airway function and the ventilation and respiratory heat exchange on exercise after pretreatment with placebo and diltiazem are compared in figure 1 . In all patients $\mathbf{s G a w}$ and $\mathrm{FEV}_{1}$ were normal before the challenge. There were no significant differences between prechallenge lung function data, exercise ventilation, inspired air temperature, or respiratory heat exchange on the two days.
The course of the airway response was similar for sGaw and $\mathrm{FEV}_{1}$ after pretreatment with placebo and diltiazem and is shown in terms of sGaw for each patient in figure 2 . It can be seen that the response to the challenge varied considerably between the patients. Apart from patient 1, pretreatment with diltiazem did not change the pattern of response. For the group as a whole there were no significant differences between the maximum bronchoconstriction or airway function at any specific time after the challenge on placebo and diltiazem days. With placebo and diltiazem pretreatment the mean (SD) maximum percentage falls of $F E V_{1}$ were $24.8(20 \cdot 1)$ and $21.7(17 \cdot 5)$. The mean (SD) maximum percentage decreases of sGaw were 66.2 $(18.4)$ and $62.7(23.9)$ respectively. The protection index calculated for each lung function measurement did not differ statistically from zero.

\section{Discusion}

In patients with exercise induced asthma diltiazem, $60 \mathrm{mg}$, taken orally four hours before exercising while they breathed cold air, did not alter the bronchoconstriction response when compared with placebo. This result clearly contrasts with the protective effect of nifedipine on exercise induced ${ }^{1-3}$ and hyperventilation induced ${ }^{10}$ asthma and with the ability of inhaled verapamil to blunt exercise induced airway obstruction. ${ }^{4}$ Three factors that could be responsible for this discrepancy must be considered-namely, the methodological, pharmacokinetic, and pharmacological aspects.

In our group of patients cold air breathing during exercise resulted in a respiratory heat exchange which was not different on the two days. As in some patients small differences in respiratory heat exchange after pretreatment with placebo and diltiazem could not be avoided, we re-evaluated the data by relating the results to the respiratory heat

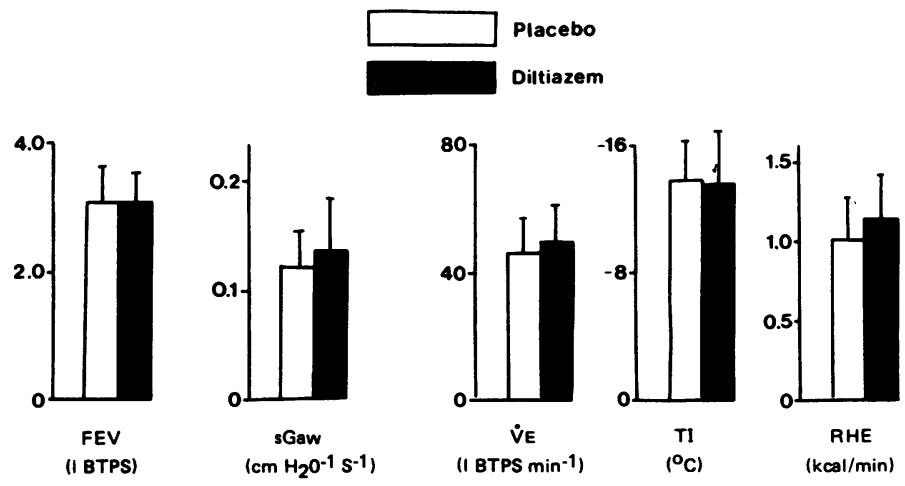

Fig 1 Comparison of the experimental conditions after pretreatment with placebo and diltiazem. FEV, and sGaw were determined before challenge (baseline values). $\dot{V}_{E}-$ minute ventilation during exercise; $T_{1}$-inspiratory air temperature; RHE-respiratory heat exchange. Statistical comparison showed no differences between the results for placebo and diltiazem. Conversion: Traditional to SI units-heat exchange: $1 \mathrm{kcal}=4 \cdot 184$ kJ. 


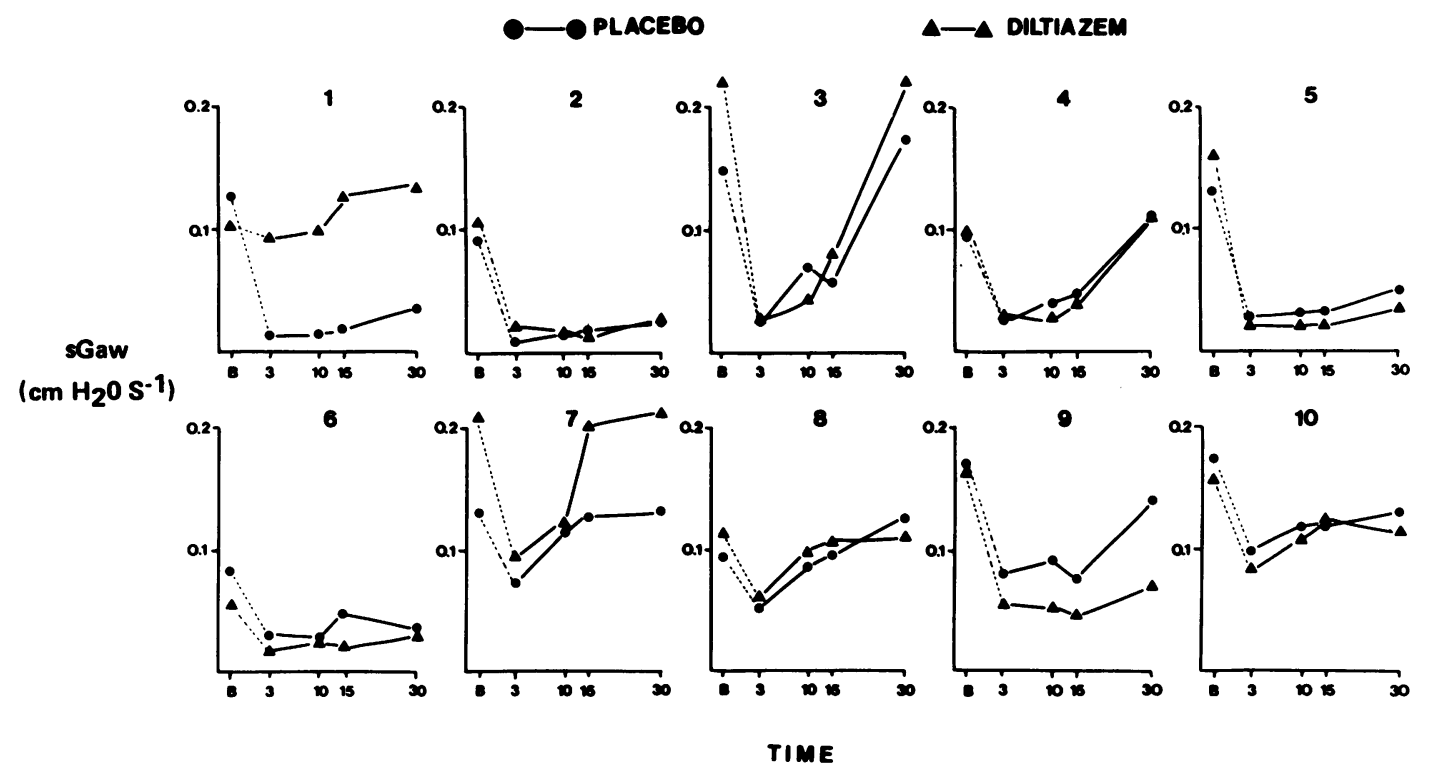

Fig 2 Time course of specific airway conductance (sGaw) after pretreatment with placebo and with diltiazem, shown for patients 1-10. B-baseline value; 3, 10, 15, 30-time (in minutes) at which lung function was measured after challenge.

exchange actually measured during the study; but this again failed to show a difference between placebo and diltiazem.

Diltiazem was given as a single dose before the challenge in the same way as in the study in which the inhibitory effect of nifedipine on exercise induced asthma was most clearly documented.' The dose used is that recommended for a single oral application of diltiazem. The choice of an interval of four hours between ingestion of the capsule and the challenge is based on pharmacokinetic data showing a peak serum concentration of diltiazem between the second and fourth hour after ingestion. "We therefore think it unlikely that pharmacokinetic factors are responsible for the different results.

The lack of effect of $60 \mathrm{mg}$ diltiazem compared with $20 \mathrm{mg}$ nifedipine could be explained simply by a relative underdosage of diltiazem. In our laboratory, however, we have shown that a $60 \mathrm{mg}$ dose of diltiazem taken orally four hours before an inhalation challenge protected against histamine and carbachol induced bronchoconstriction in patients with hyperreactive airways. After diltiazem the cumulative breath units of histamine and carbachol causing a fall in sGaw of $35 \%$ were approximately doubled (unpublished observations). As nifedipine attenuates histamine induced ${ }^{12 / 3}$ and allergen induced ${ }^{14}$ bronchoconstriction in man and diminishes airway obstruction after antigen and methacholine inhala- tion in the $\operatorname{dog}^{15}$ the ineffectiveness of diltiazem compared with nifedipine is unlikely to be simply a question of dosage. Russi et $\mathrm{al}^{16}$ recently showed in allergic sheep that verapamil prevented bronchoconstriction induced by allergen but did not modify the airway response to histamine and carbachol challenge. These results show that the effects of different calcium channel blockers in protecting against bronchoconstriction vary with the stimuli, but further studies are required to elicit the mechanisms of their actions.

The support of $E$ and $A$ Hereaus-Stiftung and of Gödecke Aktiengesellschaft, Freiburg, West Germany, is gratefully acknowledged.

\section{References}

' Cerrina J, Denjean A, Alexandre G, Lockhart A, Duroux $P$. Inhibition of exercise-induced asthma by a calcium antagonist, nifedipine. Am Rev Respir Dis 1981;123:156-60.

2 Barnes PJ, Wilson NM, Brown MJ. A calcium antagonist, nifedipine, modifies exercise-induced asthma. Thorax 1981;36:726-30.

${ }^{3}$ Patel KR. The effect of calcium antagonist, nifedipine, in exercise-induced asthma. Clin Allergy 1981;11:42932.

${ }^{4}$ Patel KR. Calcium antagonists in exercise-induced asthma. Br Med J 1981;282:932.

${ }^{5}$ Deal EC jun, McFadden ER jun, Ingram RH jun, 
Strauss RH, Jaeger JJ. Role of respiratory heat exchange in production of exercise-induced asthma. $J$ Appl Physiol 1979;46:467-75.

' West RC. Handbook of chemistry and physics. 58th ed. Cleveland, Ohio: CRC Press, 1977.

${ }^{7}$ DuBois AB, Botelho SY, Comroe JH jun. A new method for measuring airway resistance in man using a body-plethysmograph: values in normal subjects and patients with respiratory disease. $J$ Clin Invest 1956:35:327-35.

${ }^{8}$ Sachs L. Angewandte Statistik. Berlin: Springer Verlag, 1978.

${ }^{9}$ Henderson AF, Heaton JF, Costello JF. Effect of nifedipine on bronchoconstriction induced by inhalation of cold air. Thorax 1983;38:512-5.

${ }^{10}$ Solway J, Fanta $\mathrm{CH}$, Collins L, McFadden ER jun. Inhibition of bronchoconstriction during isocapnic hyperventilation of cold air by calcium channel blockers. Am Rev Respir Dis 1983;127, No 4 part 2:92 (abstract).

" Koiwaya Y, Ashihara T, Nakamura M, Etoh A. Plasma concentration of diltiazem after oral adminstration in normal volunteers. Clin Ther 1981;3:436-40.

12 Williams DO, Barnes PJ, Vickers HP, Rudolf M. Effect of nifedipine on bronchomotor tone and histamine reactivity in asthma. $\mathrm{Br} \mathrm{Med} J$ 1981;238:348.

${ }^{13}$ Malik S, O'Reilly J, Sudlow MF. Effects of sublingual nifedipine on inhaled histamine and methacholineinduced bronchoconstriction in atopic subjects. Thorax 1982;37:230 (abstract).

${ }^{14}$ Henderson AF, Heaton RW, Dunlop LS, Costello JF Effects of nifedipine on antigen-induced bronchoconstriction. Am Rev Respir Dis 1983;127:549-53.

is Brugman TM, Darnell ML, Hirshman CA. Nifedipine aerosol attenuates airway constriction in dogs with hyperreactive airways. $A m$ Rev Respir Dis 1983;127:14-7.

${ }^{16}$ Russi EW, Marchette B, Yerger L, Abraham WM, Ahmed T. Modification of allergic bronchoconstriction by a calcium antagonist: mode of action. Am Rev Respir Dis 1983;127:675-9.

$$
\text { 政 }
$$

